\title{
Diurnal and Seasonal Variation of Planetary Boundary Layer Height over East Asia and Its Climatic Change as Seen in the ERA-5 Reanalysis Data
}

\section{Kwang-Yul Kim ( $\nabla$ kwang56@snu.ac.kr)}

School of Earth and Environmental Sciences, Seoul National University https://orcid.org/0000-00018526-6737

\section{Research Article}

Keywords: diurnal/seasonal structure, boundary layer height (BLH), ERA5 reanalysis, East Asia

Posted Date: September 7th, 2021

DOI: https://doi.org/10.21203/rs.3.rs-801764/v1

License: (c) (1) This work is licensed under a Creative Commons Attribution 4.0 International License. Read Full License

Version of Record: A version of this preprint was published at SN Applied Sciences on January 4th, 2022. See the published version at https://doi.org/10.1007/s42452-021-04918-5. 


\section{Abstract}

27 The diurnal/seasonal structure of the boundary layer height (BLH) is investigated over

28 East Asia by using the hourly synoptic monthly ERA5 reanalysis variables from 1979-

29 2019. Sensible heat flux (SHF) is the major factor in the temporal and spatial variation

30 of the BLH. Although BLH, in general, is positively correlated with SHF throughout the

31 year, BLH-SHF relationship varies significantly based on the surface type, latitude and

32 time of the year. Analysis also reveals that stability is an important parameter

33 controlling the diurnal maximum BLH. The growth of BLH is strongly limited by the

34 presence of a stable layer. On the other hand, BLH increases abruptly in the presence of

35 a weakly stratified residual layer. In addition, regional warming tends to increase the

36 BLH in the mid- to high-latitude continental area. In the low-latitude continental area,

37 the sign of SHF differs seasonally and regionally. Stability plays only a minor role in the

38 BLH change except over the Tibetan Plateau, where the increased stability at the top of

39 boundary layer due to warming reduces BLH rather significantly. 


\section{Introduction}

41 The planetary boundary layer (PBL) is the lowest portion of the atmosphere, which

42 directly interacts with the Earth's surface. The portion above the PBL is called the free atmosphere, and a clear difference between the two layers is the timescale of response to surface forcing (Stull 1988; Garratt 1992; Arya 2001). Turbulence generated from the surface, by definition, is trapped within the boundary layer due to stably stratified inversion layer, also called entrainment layer, at the top of the PBL. Thus, the diurnal variation that comes from the daily insolation occurs primarily below the inversion height. In addition, exchange of heat, momentum, water, and chemical constituents between the surface and the free atmosphere occurs in the PBL, and specific features of this exchange are highly dependent on the turbulent motions in the PBL (Zang et al. 2017). In this respect, dispersion of chemical contaminants produced by human activities is closely associated with the physics of the PBL.

This study focuses on analyzing the temporal and spatial variability of the boundary layer height (BLH) over East Asia. Height of the convective boundary layer $(\mathrm{CBL})$ reflects the intensity of turbulent convection in the boundary layer. In fact, turbulent mixing is not readily obtainable from observations, but it is often parameterized in terms of the BLH (Deardorff 1970, 1972; Holtslag and Nieuwstadt 1986), which can be obtained from the vertical profiles of virtual potential temperature, water vapor mixing ratio, relative humidity, and/or wind speed. In particular, Deardorff (1970) used the vertical buoyancy flux and the BLH to calculate the velocity scale called the convective velocity, which characterizes the turbulent motions by free convection. The convective velocity and the BLH itself are the main scaling parameters in some CBL similarity hypothesis. 
The BLH is also an important variable in the study of air quality (Chen et al.

2016; Li et al. 2017; Su et al. 2018; Kim and Kim 2020). A taller PBL implies more vigorous mixing of chemical constituents in the boundary layer, so that they disperse to higher elevations and surface concentrations become lower. In this respect, the volume of the PBL can be thought of as the holding capacity of the chemical constituents emitted from the surface. Likewise, Davy and Esau (2016) considered the PBL as a reservoir for excessive heat generated at the surface, and explained the shallow PBL as a major reason for the amplified warming in the Arctic. As exemplified here, BLH is an important physical factor in elucidating diverse atmospheric phenomena.

In order to investigate the BLH from a climatological perspective, it should be ensured if the algorithm of determinining the BLH is reasonable in terms of the maximum and minimum heights of the PBL as well as their diurnal and seasonal variation. Several methods of defining the BLH have been introduced and compared (e.g., Seibert 2000; Seidel et al. 2010; Engeln and Teixeira 2013; Sawyer and Li 2013; Zhang et al. 2014). For instance, Seidel et al. (2010) computed the BLH by using the profiles of different variables such as temperature, potential temperature, virtual potential temperature, relative humidity, specific humidity, and refractivity. They addressed that uncertainty is inherent in defining the BLH in a rigorous manner regardless of the season, surface condition, and thermal stratification; each method has its own merits and demerits depending on specific situations. Intercomparison of different methods, however, is beyond the scope and will not be dealt with in this study. In the present study, the ERA5 reanalysis dataset is employed. The ERA5 reanalysis model defines the $\mathrm{BLH}$ as the minimum height for the bulk Richardson number reaching the value of 0.25 . This algorithm was proposed by Vogelezang and Holtslag (1996) and was used in recent studies (Seidel et al. 2012; Zhang et al. 2013; 
Guo et al. 2016; Guo et al. 2019). According to the 'Integrated Forecast System (IFS) documentation' of European Center for Medium-Range Weather Forecasts (ECMWF), this method is little influenced by the dataset employed (such as reanalysis, radiosonde sounding, lidar observations, etc.) and returns appropriate values both for convective and stable boundary layers.

Medeiros et al. (2005), Seidel et al. (2010), Liu and Liang (2010), Seidel et al. (2012), Engeln and Teixeira (2013), and Guo et al. (2016) described the mean state of the seasonally repeating patterns of BLH without referring to any climatological shift. Examples of BLH studies from a climatological perspective include Yang et al. (2013) and Pal and Haeffelin (2015), who examined the long-term and interannual variability of the BLH at specific sites. Zhang et al. (2013), Guo et al. (2019), and Zhang and Li (2019) investigated the observed trends of the BLH over Europe, China, and Japan respectively. They suggested several variables that are positively or negatively correlated with the climatological shift of the BLH by comparing their trends with that of the BLH. The diurnal variation of the climatological shift, however, was not examined. Variation of the BLH exhibits two primary periodicities: diurnal and seasonal cycles. It should be noted that change in the PBL depth depends significantly on the temporal scales (diurnal versus seasonal) as well as the surface types. Furthermore, BLH is spatially inhomogeneous since it is strongly influenced by the surface types and flux. Therefore, it is imperative to understand how the climatology and the impact of climate change differ depending on the time scales and the surface types.

In this study, detailed and comprehensive analysis of the BLH is conducted over East Asia together with the impact of regional warming by using the cyclostationary empirical orthogonal function (CSEOF) technique (see Kim et al. 1996; Kim and North 1997; Kim et al. 2015). While there are many studies based on observational data 
114 across the domain, main goals of the present study are (1) to investigate the variability

115 of the BLH together with the major controlling factors over the entire domain, and (2)

116 to delineate the impact of regional warming on the BLH based on the reanalysis data.

117 This study aims to depict the full spatio-temporal structure of BLH variability

118 throughout the year, thereby complementing the observational studies that generally

119 lack spatial and/or temporal details.

120 Section 2 describes the data employed in this study and the methods used to

121 analyze the data. In section 3, the fundamental features of the diurnal and seasonal

122 evolution of the BLH are investigated. The impact of regional warming on the BLH is

123 addressed in section 4, followed by concluding remarks in section 5. 


\section{Data and Method of Analysis}

125

126

127

128

129

130

131

132

133

134

135

136

137

138

139

140

141

142

143

144

145

146

147

\section{2.a. Data}

Data used in this study include monthly averaged variables at every hour of the day (also called synoptic monthly variables) for the period of 1979-2019 (41 years). Variables are analyzed over the domain $\left(70.5^{\circ}-160.5^{\circ} \mathrm{E} \times 0^{\circ}-60^{\circ} \mathrm{N}\right)$ at a $1.5^{\circ} \times 1.5^{\circ}$ resolution. Thus, there are total of 11808 (= 24 hours $\times 12$ months $\times 41$ years $)$ time steps. Based on the findings in earlier studies (e.g., Avissar and Schmidt 1988; Kettle 2015; Peng et al. 2016; Messager et al. 2012; Richardson et al. 2013; Zilitinkevich and Barlanov 2002), such surface variables as sensible heat flux, latent heat flux, sea surface temperature, surface air temperature and frictional velocity are analyzed to investigate the effect of surface forcing on the BLH. In addition, pressure (1000-200 hPa) variables including air temperatures and vertical (pressure) velocities are used to calculate the stability of the atmospheric column.

\section{2.b. Method of Analysis}

In the present study, CSEOF analysis (Kim et al. 1996; Kim and North 1997; Kim et al. 2015 ) is conducted in order to extract the diurnal/seasonal cycle of the BLH and the regional warming mode along with the associated physical variables. Unlike EOF analysis, each CSEOF loading vector describes a temporal evolution of a physically distinct mechanism (see supplementary Movie S1). Further, regression analysis in CSEOF space allows physical consistency among the evolutions of different variables. Thus, it is ideal for describing the diurnal/seasonal variation of the BLH and the impact of regional warming on it together with the responsible physical factors.

$$
\text { Each variable is subject to CSEOF analysis, which decomposes data as }
$$




$$
T(r, t)=\sum_{n} B_{n}(r, t) T_{n}(t), r=1, \cdots, M, t=1, \cdots, N
$$

149 where $B_{n}(r, t)$ are called the cylostationary loading vectors (CSLV), $T_{n}(t)$ are the 150 principal component (PC) time series, $r$ is location, and $t$ is time. Owing to the 151 cyclostationarity assumption (Kim et al. 2015; Kim 2017), CSLVs are periodic, i.e.,

$$
B_{n}(r, t)=B_{n}(r, t+d)
$$

where $d$ is called the nested period, which is 288 (= 24 hours $\times 12$ months $)$ in the

154 present study. As in EOF analysis, CSLV are mutually orthogonal and PC time series are mutually uncorrelated, i.e.,

$$
\frac{1}{M d} \sum_{t=1}^{d} \sum_{r=1}^{M} B_{n}(r, t) B_{m}(r, t)=\delta_{n m}
$$

$$
\frac{1}{N} \sum_{t=1}^{N} T_{n}(t) T_{m}(t)=\lambda_{n} \delta_{n m}
$$

where $\lambda_{n}$ are eigenvalues (variance of $T_{n}(t)$ ), and $\delta_{n m}$ is the Kronecker delta. Thus,

CSLVs are mutually uncorrelated and orthogonal evolutions extracted from the given variable.

In a typical setting, many variables are analyzed in order to understand the physical mechanism behind each CSEOF mode. For example, another variable is decomposed as

$$
P(r, t)=\sum_{n} C_{n}(r, t) P_{n}(t),
$$

where $C_{n}(r, t)$ are the CSLVs and $P_{n}(t)$ are the PC time series of variable $P(r, t)$. The two sets of decomposition in (1) and (5) are not physically consistent in that $T_{n}(t) \neq P_{n}(t)$

167 in general. In order to make the two sets physically consistent, regression analysis is conducted in CSEOF space between the so-called "target" variable $T(r, t)$ and the "predictor" variable $P(r, t)$. It is a two-step process: 


$$
\text { Step 2: } C_{n}^{(\mathrm{reg})}(r, t)=\sum_{k=1}^{K} \alpha_{k}^{(n)} C_{k}(r, t), \quad n=1,2, \cdots,
$$

172 where $K(=20$ in this study) is the number of CSEOF modes used for regression. Then,

173 the two variables can be written, aside from a small regression error, as

174

$$
\{T(r, t), P(r, t)\}=\sum_{n}\left\{B_{n}(r, t), C_{n}^{(\mathrm{reg})}(r, t)\right\} T_{n}(t)
$$

175 This procedure can be repeated for as many predictor variables as needed. Then, the

176 entire dataset can be written as

177

$$
\{\operatorname{Data}(r, t)\}=\sum_{n}\left\{B_{n}(r, t), C_{n}^{(\mathrm{reg})}(r, t), D_{n}^{(\mathrm{reg})}(r, t), \cdots\right\} T_{n}(t)
$$

178 where the terms in curly braces represent CSLVs for different variables. The "regressed" 179 CSLVs are physically consistent with $B_{n}(r, t)$ in that they all share the same PC time 180 series $T_{n}(t)$ 


\section{Results and Discussion}

182

183

\section{3.a. Seasonal Patterns of Maximum and Minimum Boundary Layer Height}

The first CSEOF mode represents the diurnal/seasonal cycle of the BLH. Figure 1 shows the daily maximum BLH (shade) and the minimum BLH (contour) derived from the loading vector of the first CSEOF mode (see Movie. S1 for the full loading vector). In January (representing the winter months), both the maximum and the minimum BLH over the continent are generally lower than those in the other months; typical minimum values are found in January or December (Fig. 2b, d). Over the ocean, on the contrary, both the maximum and the minimum BLH are higher than those in the other months; maximum values are typically found in January or February (Fig. 2a, c; see also Liu et al. 2015; Chien et al. 2019). In April (representing the spring months), maximum BLH increases significantly over the continent reaching the annual maximum values in May or June (Fig. 2a). Over the ocean both the maximum and the minimum BLH decrease slightly. In July (representing the summer months), the maximum and the minimum BLH slightly decrease over the continent compared to the spring months. Over the ocean, both the daily maximum and the minimum BLH exhibit the annual minimum values in summer (Fig. 2b, d). In October (representing the fall months), maximum BLH begins to decrease over the continent, and the minimum BLH begins to increase over the ocean.

For each month, the PC time series of the seasonal cycle exhibits small interannual fluctuations of about $\pm 5 \%$ with respect to the mean value (Fig. 1e). The amplitude of the seasonal cycle shows strong monthly variation with a maximum in May and a minimum in November. This peculiar behavior indicates that the inter-annual modulation effect on the amplitude of the seasonal cycle differs from one month to another, with a stronger modulation tends to be in May and a weaker one in November. 
The structure of the seasonal evolution of the BLH over the domain is generally

207 similar to that over Europe with a seasonal maximum around July (Pal and Haeffelin 208 2015). The seasonal patterns of the daily maximum BLH over China are reasonably 209 similar to those estimated from the CALIPSO (Cloud-Aerosol Lidar and Infrared 210 Pathfinder Satellite Observation; Liu et al. 2015). As noted in Liu et al. (2015), however, some differences both in terms of the amplitude and the phase of the seasonal BLH are seen between the CALIPSO and the ECMWF datasets. The annual and seasonal patterns of the BLH at specific hours (see Fig. S1 and the discussion therein) are also similar to the estimates based on the sounding data in China (Zhang et al. 2018; Guo et al. 2016). Contrast in the seasonal evolution patterns of the maximum BLH over the ocean and the continent is also similar to that in Chan and Wood (2013) and Medeiros et al. (2005). Compared with the eastern North Pacific (Luo et al. 2016), western North Pacific exhibits a stronger seasonality in the variation of the BLH (Fig. 1).

\section{3.b. Physical Factors Governing Maximum and Minimum Boundary Layer Height}

Figure 3 shows the pattern of frictional velocity together with the minimum BLH. Frictional velocity is given by

$$
v^{*}=\left(\overline{u^{\prime} w^{\prime}}+\overline{v^{\prime} w^{\prime}}\right)^{1 / 2}
$$

which represents the horizontal eddy momentum carried by vertical eddies (Stull 1988; Holton 2004). Eddy momentum flux is much higher over the ocean than over the continent, which implies that the mechanical production of eddy kinetic energy is stronger over the ocean than over the continent. There is only small seasonal variation of the frictional velocity over the continent, while the frictional velocity is much higher in cold months than in warm months over the ocean. This is primarily due to the increased lower tropospheric stability and wind (Vickers et al. 2015) and is partly due 
to the increased vertical velocity associated with the seasonal variation of the

232 temperature difference between the sea surface and surface air (see Fig. S2). As can be

233 seen in the figure, frictional velocity is a good indication of the minimum BLH both over

the continent and over the ocean; pattern correlation is 0.64 over the continent and is 0.66 over the ocean.

Figure 4 shows the pattern of SHF over land and that of LHF over the ocean together with the maximum BLH. Energy budget in the PBL is described as (de Arellano et al. 2015; Stull 1988; Yi et al. 2001)

$$
h \frac{D\langle\theta\rangle}{D t}=-\left.\overline{\theta^{\prime} w^{\prime}}\right|_{S} ^{T}-\frac{1}{\bar{\rho} c_{p}} \Delta F_{z}
$$

where $\langle\theta\rangle$ is the mean potential temperature in the PBL, $\overline{\theta^{\prime} w^{\prime}}$ is the heat flux at the surface $(S)$ and the top $(T)$ of the PBL, and $\Delta F_{z}$ is the longwave radiative forcing. An increase in the surface heat flux, then, increases the maximum BLH assuming that the heat flux at the PBL top is small compared to the surface heat flux. Radiative forcing is neglected in the present study. As can be seen, the pattern of SHF (LHF) matches reasonably with that of maximum BLH over land (ocean). It appears that the maximum BLH increases as SHF (LHF) increases over the continent (ocean) (Medeiros et al. 2005; Pal and Haeffelin 2015). There is a substantial difference between the continent and the ocean in terms of the relative magnitude of the maximum BLH to that of the heat flux. It should be noted that SHF (LHF) is mainly responsible for the variation of the maximum BLH over land (the ocean); pattern correlation is 0.75 (0.56) over land (ocean).

\section{3.c. The Diurnal Structure of Boundary Layer Height}

Figure 5 shows the diurnal structure of stability, together with the BLH for each season along $40^{\circ} \mathrm{N}, 25^{\circ} \mathrm{N}$, and $55^{\circ} \mathrm{N}$. See also the supplementary information (Movie S1 and Figs. 
S4, S6, and S8) for a fuller depiction of the diurnal and seasonal structures of the BLH together with stability. Stability is measured in terms of the stability parameter

$$
S_{p}=-T \frac{\partial \ln \theta}{\partial p}=-\frac{T}{\theta} \frac{\partial \theta}{\partial p},
$$

and is converted to the temperature change per $25 \mathrm{hPa}$ drop in pressure.

In January, stability quickly rises from the surface over the continent, limiting turbulent mixing close to the surface in the morning (see January 22 UTC in Fig. 5a, b, c). During the daytime, BLH increases by $\sim 1-1.5 \mathrm{~km}$ up to the base of the entrainment layer with stability greater than $1.5 \mathrm{~K}$ per $25 \mathrm{hPa}$ (see January 07-09 UTC in Fig. 5a, b, c). Over the ocean, BLH is fairly high throughout the day. As already discussed in conjunction with Fig. 4, LHF is highly correlated in pattern with the maximum BLH over the ocean. The release of a large amount of oceanic LHF is manifested as weak stability in the low troposphere (see January in Fig. 5). As a result, the maximum BLH over the ocean is relatively high.

In April, the morning BLH is seen near the level of maximum stability over the continent (see April 20-21 UTC in Fig. 5a, b, c). Above the layer of maximum stability, a thick layer of weak stability is found. This relatively well-mixed layer, which may be a leftover from the daytime PBL, is known as the residual layer (Stull 1988). During the daytime, stability decreases near the surface so that turbulent mixing penetrates the layer of weak stability and BLH jumps to a much higher elevation (see April 08-10 UTC in Fig. 5). Over the ocean, BLH is relatively low as the release of latent heat is reduced. In July, situation is similar to that in April with a large diurnal excursion of the BLH over the continent and a shallow boundary layer over the ocean (see July in Fig. 5). It is typically between April and July when the BLH reaches a maximum in mid- to highlatitude land areas (Fig. 2). 
In October, a morning layer of high stability near the surface results in a shallow

280

PBL over the continent (see right panels of October in Fig. 5). During the daytime, stability decreases appreciably, resulting in an increased BLH (left panels of October in Fig. 5). Over the ocean, BLH begins to increase because of the increased LHF. It appears that the diurnal cycle of the BLH is strongly controlled by SHF over the continent. Figure 6 shows the diurnal structure of SHF, BLH, and the stability at the top of the BLH (see also supplementary Figs. S3, S5 and S7). During the cold months (Jan, Nov), BLH over the continent increases as SHF increases during the daytime. It appears that stability poses a strong restriction as to the maximum height of BLH; BLH rises until it encounters a relative stable layer (red dots). During the warm months, when the layer of relatively low stability is fairly thick, BLH increase significantly as the daytime SHF increases. In particular, BLH jumps to $\sim 2.5 \mathrm{~km}$ above the surface in May-July along $40^{\circ} \mathrm{N}$ (see also Liu and Liang 2010; Pal and Haeffelin 2015; Chu et al. 2019). The maximum rise of the BLH seems to be controlled primarily by SHF but is also limited by the stability. BLH rises typically until it encounters a stable layer, although the top of the PBL tends to reach the elevation of higher stability as the magnitude of SHF increases. In the late afternoon, BLH begins to decrease as SHF diminishes (Lothon et al. 2014). A sharp drop in the BLH is observed around the midnight and stays low until the next morning (see also Fig. 4 in Hegarty et al. (2018)). Over the Indian subcontinent and the surrounding oceans, the diurnal variation of the BLH exhibits a structure similar to that in Sathyanadh et al. (2017). Over the ocean, the BLH exhibits a much flatter diurnal cycle (Liu and Liang 2010; Luo et al. 2016).

A relationship between SHF, BLH, and stability is examined in Fig. 7. In general, SHF and BLH are positively correlated. The bins with the red dots (higher occurrence frequencies) near the origin largely represent the events after the sunset until the 
sunrise. As should be expected there is a strong seasonal variation in the maximum BLH

305

306

307

308

309

310

311

312

313

314

315

316

317 and maximum SHF. The spring season exhibits the largest range of the BLH and SHF, whereas the fall season exhibits the smallest range. In general, the upper limb (with higher ratios of BLH to SHF) of the spread is associated with lower stability than the lower limb with lower ratios of BLH to SHF. On the other hand, the far end of the spread (strong SHF and/or large BLH) exhibits a wider range of stability from 1 to 2 . The bins with tall boundary layers in DJF and MAM consist largely of the cases from the Tibetan Plateau (see Fig. S9). This indicates that the BLH responds more strongly to SHF over the Tibetan Plateau (see also Fig. 4). It seems that a thick residual layer is formed over the top of the Tibetan Plateau in spring and winter. As SHF increases during the day, stability near the top of the Tibetan Plateau decreases, and BLH jumps to the top of the residual layer. The anomalously high PBL over the Tibetan Plateau region in winter and spring is also discussed in Chen et al. (2016). They asserted that the upper-level PV structures and the jet position as well as the surface condition and heat flux are important factors for the BLH because of the high orography of the Tibetan Plateau. It should be noted that the BLH climatology over the Tibetan plateau differs significantly among different reanalysis datasets; it is cautioned that physical relationship may vary depending on a particular reanalysis dataset employed because of the model biases and errors in these extreme conditions. Over the ocean, the role of the stability is unclear (see Fig. S10), although there is a general linear relationship between the BLH and LHF (and SHF). 


\section{The Effect of Regional Warming}

326 Figure 8 shows the second CSEOF mode, which depicts the effect of regional warming 327 on the BLH. The corresponding PC time series shows a positive trend (Fig. 8e), which clearly indicates that this mode is associated with regional warming (see also surface air temperature in Fig. S11). The net effect of regional warming during the 1979-2019 period is determined to be approximately 1.6 (change in the PC amplitude between 1979 and 2019) times the loading patterns in Fig. 8 (see also Eq. (1)). The PC time series exhibits strong seasonal variations, suggesting that the effect of warming differs from one month to another. On top of the trend, inter-annual fluctuations in the PC time series indicate that warming also arises due to natural sources. While a linear fit is used in Fig. 8e, the rate of increase seems to vary on decadal time scales. In particular, warming trend seems to be much lower during 2004-2019 compared with that during 1989-2003 (see also Fig. S12 and discussion therein). This result seems to be roughly consistent with the finding in Guo et al. (2019; see their Fig. 2).

In January, maximum BLH has decreased over the mid-latitude region of the Asian inland, while it has increased over the ocean. The minimum BLH has generally increased over the whole domain except over the mid-latitude inland China. In April, the maximum BLH has increased by $50 \mathrm{~m}$ or more over the continent except over the Tibetan Plateau and India. The minimum BLH has decreased over the northern part and increased over the southern part of the domain (mainly over the ocean). In July, fairly significant increases $(>100 \mathrm{~m})$ in the maximum BLH are seen over much of East Asia with a reduction in the minimum BLH to the north of $\sim 20^{\circ} \mathrm{N}$. In October, a slight increase in the maximum BLH is seen over the continent with a reduction in the minimum BLH in the mid- and low-latitude land areas. As in earier studies (Zhang et al. 2013 in Europe; Guo et al. 2019 in China), BLH averaged over the entire domain shows 
a positive trend in association with warming. On the other hand, trend is not unform spatially with even negative values around the Indian subcontinent particularly in winter and spring (see also Li et al. 2020).

As shown in section 3, SHF plays an important role in the growth of the boundary layer. Figure 9 shows surface heat flux anomalies in comparison with the maximum BLH anomalies for the regional warming mode. Change in the maximum BLH due to warming is generally consistent with the change in SHF (LHF) over land (ocean); pattern correlation is $0.74(0.56)$ over land (ocean). The maximum BLH tends to increase as SHF increases and the opposite is true. SHF has increased in the northern part of the inland Asia, but decreased over India, Indochina, and Tibet. Positive correlation between SHF and the maximum BLH is more robust in the warm season (May, Jul, Sep) than in the cold season (Jan, Mar, Nov).

Over the ocean, LHF has increased due to warming except over the Northern Pacific (see Fig. 9). In March and November, significantly increased heat flux is seen near the Kuroshio Current and its extension in the latitude band of $20^{\circ}-35^{\circ} \mathrm{N}$. This leads to increased max BLH in March and November (see also Fig. S13b). On the other hand, decreased BLH is seen in March and November north of $\sim 40^{\circ} \mathrm{N}$ (see Fig. S13a, c).

It should be noted that change in the maximum BLH is not quite proportional to that of SHF (see Fig. 9). As we have already discussed in conjunction with Fig. 5, static stability may be an important parameter controlling the PBL. The colored contours in Fig. 5 exhibit change in static stability under regional warming. It should be noted that there have been noticeable changes in the vertical structure of the atmosphere as well as the surface condition due to warming. Since turbulence generated from the surface is trapped in the lower troposphere below a strongly stratified layer, change in the static stability may alter the height that turbulent eddies can rise. Guo et al. (2019) also 
investigated the stability change in comparison with the inter-annual trend of the BLH. They used the lower tropospheric stability defined as the potential temperature difference between the 700-hPa level and the surface. In the present study, static stability $\left(S_{p}\right.$; Eq. 12$)$ is calculated at the top of boundary layer where turbulence that originated from below encounters strong resistance.

Figure 10 displays the anomalous stability at the top of the climatological PBL in the SHF-BLH space for the different seasons. Again, there is, in general, a positive correlation between SHF and BLH changes (see also Fig. S13). SHF has generally increased due to regional warming as indicated by a larger number of dots on the positive side of $\triangle \mathrm{SHF}$ except in DJF. In the winter and spring seasons, there is a large number of bins scattered in the third quadrant, many of which represent infrequent events. The pattern of scattering indicates that the degree of BLH reduction to decreased SHF varies widely in winter and spring. As can be seen, stability at the top of the climatological BLH has generally decreased throughout the year. This suggests that change in SHF is the primary factor for the BLH change in conjunction with regional warming, and change in stability generally does not play a major role. There are, however, some notable exceptions. For example, many bins in the second quadrant in winter and spring exhibit significantly lowered stability. These bins represent the highlatitude regions of East Asia. It appears that the BLH has increased even though SHF has decreased, because stability has decreased significantly at the top of the climatological boundary layer.

It is known that turbulence can develop even in stably stratifieyd upper troposphere near the jet stream because of the strong vertical wind shear (Clem 1955; Reiter and Nania 1964). Thus, the jet stream can contribute substantially to the growth of the boundary layer over the Tibetan Plateau. In response to regional warming, the 
400 BLH over the Tibetan Plateau decreased significantly in winter and spring due to the 401 decreased SHF and increased stability at the top of PBL (see Fig. S14). Judging from the 402 higher frequency of bins along the $y$ axis, it appears that stability is the main reason for 403 the reduction of BLH in these seasons (see also Movie S1). The dramatic change of 404 stability over this region could be attributed to the change in the position of the jet 405 stream in response to warming. A shift of the jet stream may be explained by the 406 meridionally asymmetric warming pattern (see Fig. S11) in the context of the thermal 407 wind balance. 


\section{Summary and Concluding Remarks}

409

410

411

412

413

414

415

416

417

418

419

420

421

422

423

424

In this study, the daily and seasonal cycles of the BLH was investigated in East Asia together with the impact of regional warming by using the hourly synoptic monthly ERA5 reanalysis variables. The diurnal structure of the BLH changes appreciably with the season in terms of the minimum/maximum height of the boundary layer, and exhibits strong season-dependent spatial variation related to the surface type, elevation, and latitude (Fig. 1).

Over the continent, SHF is a major factor determining the maximum BLH throughout the day (Figs. 4 and 6). There is a strong positive correlation between the two variables, although the slope of the linear relationship varies significantly from one month to another and from one location to another (Fig. 7); this seems to be associated with several different factors including the surface type and the vertical structure of stability of the atmospheric column. The maximum BLH is achieved $\sim 2-3$ hours after the maximum SHF in the warm months (Fig. 6). The static stability of the atmospheric column, to a lesser extent, also exerts influence on the maximum BLH, particularly in the cold months (Fig. 5). A strong stability above the cold continental surface in winter often limits the growth of the BLH. In the absence of surface heat flux, the minimum BLH is largely controlled by mechanical production of eddies measured by the frictional velocity (Fig. 3).

Over the continent, the maximum BLH varies with the seasonal variation of SHF and, to a lesser extent, static stability of air (Fig. 6). The seasonal maximum BLH is observed typically between April and July north of $\sim 40^{\circ} \mathrm{N}$, and August-September and March-April to the south of $\sim 40^{\circ} \mathrm{N}$ (Fig. 2). The Tibetan Plateau is an exception with the maximum BLH being observed in February. The seasonal minimum BLH is seen in December over much of the continent. The low-latitude regions including India, the 
Indochina Peninsula, and the Tibetan Plateau, on the other hand, exhibit the seasonal minimum BLH in the warm months. It should be mentioned that the presence of a residual layer is an important seasonal factor controlling the maximum BLH. In the presence of a weakly stratified residual layer, turbulent motion easily reaches the top of the residual layer with the aid of surface forcing. As a result, diurnal variation of BLH becomes strong. The seasonal patterns of the minimum BLH show complex patterns with a strong latitudinal and regional dependency (Fig. 2c and d).

Over the ocean, LHF rather than SHF seems more strongly related to the maximum BLH. While the diurnal variation of the BLH over the ocean is not significant, seasonal variation is relatively strong. In particular, the maximum BLH varies from $\sim 100 \mathrm{~m}$ in July to $\sim 1.5 \mathrm{~km}$ in January over the northern North Pacific (Fig. 4). Over the low-latitude ocean, seasonal variation of the BLH is not so dramatic.

For the regional warming mode, changes in SHF and BLH, in general, display positive correlations (Fig. 10). SHF has generally increased over much of the mid- and high-latitude continental domain due to regional warming except perhaps in spring (Fig. 9). Static stability at the top of the boundary layer has also decreased, in general, due to warming (Fig. S13a and c). This implies that turbulence can reach a higher elevation, thereby increasing the BLH under regional warming over the mid- and high-latitude continental areas. Over the low-latitude continental area, on the other hand, SHF has decreased (increased) on the western (eastern) side of the domain throughout the year. The daytime static stability is generally consistent in sign with the SHF. This implies that BLH reduction (augmentation) is observed on the western (eastern) side of the continent (Fig. 9). A clear exception is July, when the BLH has increased over the western part of the low-latitude continental area even though SHF has decreased (Fig. 
458 fluctuations can come by several different sources such as the regional monsoons, sea

459 ice reduction in the Arctic, and El Niños in addition to a steady increase in the

460 concentration of greenhouse gases (Fig. 8e). As a result, the slope of the BLH change can

461 vary significantly from one period to another. For example, trend is strongly positive

462 during 1985-2003, while it is negative during 2003-2013 (see also Fig. S12 and the

463 discussion therein).

464 This is the first time that the diurnal/seasonal cycle of BLH is analyzed and 465 discussed in its full detail over East Asia together with the impact of regional warming.

466 While the use of reanalysis products poses crucial limitations, this study aims to

467 complement the observational studies with somewhat localized scope in space and time

468 by providing the full spatio-temporal structure of BLH variability throughout the year.

469 We hope that this study serves as (1) useful guideline for improving the boundary layer

470 physics in computer models, (2) basic information on the spatio-temporal structure of

471 boundary layer in East Asia, and (3) a benchmark solution aiding more localized and

472 detailed analysis of the BLH and its physics. In closing, it should be noted that the BLH

473 climatology from the ERA5 reanalysis product in the present study can be different

474 from those of the other reanalysis datasets and observations particularly over the 475 Tibetan plateau. 
References

477 Arya SP (2001) Introduction to Micrometeorology. Academic Press, San Diego, 420 pp.

478 Avissar R, Schmidt T (1998) An evaluation of the scale at which ground-surface heat 479 flux patchiness affects the convective boundary layer using large-eddy 480 simulations. J Atmos Sci 55(16):2666-2689.

481

482

483

Chan KM, Wood R (2013) The seasonal cycle of planetary boundary layer depth determined using COSMIC radio occultation data. J Geophys Res-Atmos $118: 12422-12434$

484

485

486

Chen X, Škerlak B, Rotach MW, et al (2016) Reasons for the extremely high-ranging planetary boundary layer over the western Tibetan Plateau in winter. J Atmos Sci 73:2021-2038

487

488

489

490

491 $36: 53-60$

492

493

Davy R, Esau I (2016) Differences in the efficacy of climate forcings explained by Western North Pacific based on GPS radio occultation, island soundings, and numerical models. Sensors 19:155.

Clem LH (1955) Clear-air turbulence near the jet-stream maxima. Bull Am Meteor Soc

494 variations in atmospheric boundary layer depth. Nat Comm 7:11690.

de Arellano JV, van Heerwaarden CC, van Stratum BJH, van den Dries K (2015) 495 Atmospheric boundary layer. Cambridge Univ Press, New York, p 265.

Deardorff JW (1970) Convective velocity and temperature scales for the unstable 497 498 planetary boundary layer and for Rayleigh convection. J Atmos Sci 27:12111213.

499

Deardorff JW (1972) Parameterization of the planetary boundary layer for use in 500 general circulation models. Mon Wea Rev 100:93-106. 
501 Engeln AV, Teixeira J (2013) A planetary boundary layer height climatology derived from ECMWF reanalysis data. J Clim 26:6575-6590.

503 Garratt JR (1992) The atmospheric boundary layer. Cambridge University Press, $504 \quad$ Cambridge, 316 pp.

505

Guo J, Miao Y, Zhang Y, et al (2016) The climatology of planetary boundary layer height

506 in China derived fromradiosonde and reanalysis data. Atmos Chem Phys

507 16:13309-13319.

508

Guo J, Li Y, Cohen JB, et al (2019) Shift in the temporal trend of boundary layer height in 509 China using long-term (1979-2016) radiosonde data. Geophys Res Lett 46:6080510 6089.

511 Hegarty JD et al. (2018) Analysis of the planetary boundary layer height during 512 DISCOVER-AQ Baltimore-Washington, D.C., with lidar and high-resolution WRF modeling. J Appl Meteor and Clim 57:2679-2696.

514 Holton JR (2004) An Introduction to dynamic meteorology, 4th Ed, Elsevier, $515 \quad$ Amsterdam, p 529.

516 Holtslag AAM, Nieuwstadt FTM (1986) Scaling the atmospheric boundary layer. Boundary-Layer Meteorol 36:201-209.

518 Kettle AJ (2015) A diagram of wind speed versus air-sea temperature difference to 519 understand the marine atmospheric boundary layer. Energy Procedia, 76:138520 147.

521 Kim K-Y, North GR, Huang J (1996) EOFs of one-dimensional cyclostationary time series: Computations, examples, and stochastic modeling. J Atmos Sci 53:10071017.

524 Kim K-Y, North GR (1997) EOFs of Harmonizable Cyclostationary Processes. J Atmos Sci 
526 Kim K-Y, Hamlington B, Na H (2015) Theoretical foundation of cyclostationary EOF

527

528

529

530

531

532

533

534

535

536

537

538

539

540

541

542

543

544

545

546

547

548

549

550 analysis for geophysical and climatic variables: Concepts and examples. Earth-Sci Rev 150:201-218.

Kim K-Y (2017) Cyclostationary EOF Analysis: Theory and Applications, SNU press, Korea, p 446.

Kim S-U, Kim K-Y (2020) Physical and chemical mechanisms of the daily-to-seasonal variation of PM10 in Korea. Sci Total Environ 712:136429.

Li J, Chu Y, Li X, Dong Y (2020) Long-term trends of global maximum atmospheric mixed layer heights derived from radiosonde measurements. Environ Res Lett 15:034054.

Li Z, Guo J, Ding A, et al (2017) Aerosol and boundary-layer interactions and impact on air quality. Natational Sci Rev 4:810-833.

Liu J, Huang ل Chen B, Zhou T, Yan H, Jin H, Huang Z, Zhang B (2015) Comparison of PBL heights derived from CALIPSO and ECMWF reanalysis data over China. J Quantitative Spectroscopy and Radiative Transfer 153:102-112.

Liu S, Liang X-Z (2010) Observed Diurnal Cycle Climatology of Planetary Boundary Layer Height. J Clim 23:5790-5809.

Lothon M et al. (2014) The BLLAST field experiment: Boundary-layer late afternoon and sunset turbulence. Atmos Chem Phys, 14, 10931-10960.

Luo T, Wang Z, Zhang D, Chen B (2016) Marine boundary layer structure as observed by A-train satellites. Atmos Chem Phys 16:5891-5903.

Medeiros B, Hall A, Stevens B (2005) What Controls the Mean Depth of the PBL? J Clim $18: 3157-3172$.

Messager C, Speich S, Key E (2012) Marine atmospheric boundary layer over some Southern Ocean fronts during the IPY BGH 2008 cruise. Ocean Sci 8:1001-1023. 
Pal S, Haeffelin M (2015) Forcing mechanisms governing diurnal, seasonal, and interannual variability in the boundary layer depths: Five years of continuous lidar observations over a suburban site near Paris. J Geophys Res-Atmos. 120:11936-11956,

Peng S, Zhu Y, Huang K, Ding, X, Shi R, Wu D, Feng Y, Wang D (2016) Detecting the structure of marine atmospheric boundary layer over the Northern South China Sea by shipboard GPS sondes. Atmos Sci Lett 17:564-568.

Petäjä T, Järvi L, Kerminen V-M, et al (2016) Enhanced air pollution via aerosolboundary layer feedback in China. Scientific Rep 6:18998.

Reiter ER, Nania A (1964) Jet-stream Structure and clear-air turbulence (CAT). J Appl Meteor 3:247-260.

Richardson H, Basu S, Holtslag AAM (2013) Improving stable boundary-layer height estimation using a stability-dependent critical bulk Richardson number. Boundary-Layer Meteor 148:93-109.

Sathyanadh A, Prabhakaran T, Patil C, Karipot A (2017) Planetary boundary layer height over the Indian subcontinent: Variability and controls with respect to monsoon. Atmos Res 195:44-61.

Seibert P (2000) Review and intercomparison of operational methods for the determination of the mixing height. Atmos Environ 34:1001-1027.

Seidel DJ, Ao CO, Li K (2010) Estimating climatological planetary boundary layer heights from radiosonde observations: Comparison of methods and uncertainty analysis. J Geophys Res 115:D16113.

Seidel DJ, Zhang Y, Beljaars A, et al (2012) Climatology of the planetary boundary layer over the continental United States and Europe. J Geophys Res-Atmos 117:D17106. 
576 Stull RB (1988) An introduction to boundary layer meteorology. Kluwer Academic, 577 Dordrecht, $652 \mathrm{pp}$.

578 Su T, Li Z, Kahn R (2018) Relationships between the planetary boundary layer height

579

580

581

582

583

584

585

586

587

588

589

590

591

592

593

594

595

596

597

598

599

600 and surface pollutants derived from lidar observations over China: regional pattern and influencing factors. Atmos Chem Phys 18:15921-15935.

Vickers D, Mahrt L, Andreas EL (2015) Formulation of the sea surface friction velocity in terms of the mean wind and bulk stability. J Appl Meteor Clim 54:691-703.

Vogelezang DHP, Holtslag AAM (1996) Evaluation and model impacts of alternative boundary-layer height formulations. Boundary-Layer Meteor 81:245-269.

Yang D, Li C, Lau AK-H, Li Y (2013) Long-term measurement of daytime atmospheric mixing layer height over Hong Kong. J Geophys Res-Atmos 118:2422-2433.

Yi C, Davis KJ, Berger BW, Bakwin PS (2001) Long-term observations of the dynamics of the continental planetary boundary layer. J Atmos Sci 58:1288-1299.

Zang Z, Wang W, Cheng X, Yang B, Pan X, You W (2017), Effects of boundary layer height on the model of ground-level PM2.5 concentrations from AOD: Comparison of stable and convective boundary layer heights from different methods. Atmos 8(6):104.

Zhang W, Guo J, Miao Y, Liu H (2018) On the summertime planetary boundary layer with different thermodynamic stability in China: A radiosonde perspective. J Clim 31:1451-1465.

Zhang Y, Gao Z, Li D, et al (2014) On the computation of planetary boundary-layer height using the bulk Richardson number method. Geoscientific Model Development 7:2599-2611.

Zhang Y, Li S (2019) Climatological characteristics of planetary boundary layer height over Japan. Int J Climatol 39:4015-4028. 
601 Zhang Y, Seidel DJ, Zhang S (2013) Trends in Planetary Boundary Layer Height over 602 Europe. J Clim 26:10071-10076.

603 Zilitinkevich S, Barlanov A (2002) Calculation of the height of the stable boundary layer 604 in practical applications. Boundary-Layer Meteor, 105:389-409. 
606 Figure 1. (a-d) The seasonal patterns of daily maximum (shade; km) and daily 607 minimum (contour lines; km) height of planetary boundary layer for the first CSEOF mode (diurnal/seasonal cycle). (e) The normalized PC time series of the seasonal cycle. Contour interval is $0.1 \mathrm{~km}$ with the black contour at $0.5 \mathrm{~km}$ (blue $<0.5 \mathrm{~km}<\mathrm{red}$ ). The blue curves in (e) denote the PC time series in May and November, and the blue dotted

611 lines represent their mean values.

612

Figure 2. Month of (a) maximum BLH_max, (b) minimum BLH_max, (c) maximum BLH_min, and (d) minimum BLH_min. The red colors represent warm months and the blue colors cold months. The numbers on the map denote the months of the respective colors.

Figure 3. The patterns of frictional velocity (shade; $\mathrm{cm} \mathrm{s}^{-1}$ ) together with the minimum boundary layer height (blue contours $<1.0$ (black) $<$ red contours at $0.1 \mathrm{~km}$ interval) for the diurnal/seasonal cycle mode.

Figure 4. The patterns of sensible heat flux over the continent and latent heat flux $(\div 3)$ over the ocean (shade; $\mathrm{W} \mathrm{m}^{-2}$ ) together with the maximum boundary layer height (blue contour lines at $0.1 \mathrm{~km}$ interval $<1.0$ (black) $<$ red contour lines at $0.3 \mathrm{~km}$ interval) for the diurnal/seasonal cycle mode.

622 Figure 5. The vertical structure of stability (shade; $S_{p} \times 25 \mathrm{~K} \mathrm{hPa}^{-1}$ ) and its change due to regional warming (blue $<0<$ red contours; $S_{p} \times 2500 \mathrm{~K} \mathrm{hPa}^{-1}$ ), and the boundary

624 layer height (thick black line) at the approximate time of the maximum height (left 625 column) and the minimum height (right column): (a) $40^{\circ} \mathrm{N}$, (b) $25^{\circ} \mathrm{N}$, and (c) $55^{\circ} \mathrm{N}$.

Figure 6. The diurnal structure of boundary layer height (contours; $0.2 \mathrm{~km}$ interval up to $1.0 \mathrm{~km}$ and $0.5 \mathrm{~km}$ interval thereafter) together with sensible heat flux (shade; $\mathrm{W} \mathrm{m}^{-2}$ ) over the continent, latent heat flux (shade; $\mathrm{W} \mathrm{m}^{-2}$ ) over the ocean, and stability at the top of the boundary layer (color dots; $S_{p} \times 25 \mathrm{~K} \mathrm{hPa}^{-1}$ ) for the first CSEOF mode 
630 (diurnal/seasonal cycle). The upper color bar represents the shading levels for heat flux,

631 and the lower color bar the dot color levels for stability: (a) $40^{\circ} \mathrm{N}$, (b) $25^{\circ} \mathrm{N}$, and (c) $55^{\circ} \mathrm{N}$.

632 Figure 7. Seasonal scatter plot of stability (shade; $S_{p} \times 25 \mathrm{~K} \mathrm{hPa}^{-1}$ ) over land in SHF-

633 BLH space for the first CSEOF mode (diurnal/seasonal cycle): (a) DJF, (b) MAM, (c) JJA,

634 and (d) SON. The colored dots represent the occurrence frequency per day.

635 Figure 8. (a-d) The seasonal patterns of daily maximum (shade; $m$ ) and daily minimum

636 (contour; m) height of planetary boundary layer for the warming mode. (e) The PC time

637 series of the warming mode (red curve) together with the linear trend (black line).

638 Contour interval is $5 \mathrm{~m}$ (blue $<0<$ red). The blue curves represent the PC time series for

639 January and July, and the blue dotted lines their respective trends.

640 Figure 9. The patterns of anomalous sensible heat flux over the continent and

641 anomalous latent heat flux $(\div 3)$ over the ocean (shade; $\mathrm{W} \mathrm{m}^{-2}$ ) together with the change

642 in maximum boundary layer height (blue $<0<$ red contour lines at $\pm 10,20$, and at $20 \mathrm{~m}$

643 interval thereafter) for the warming mode.

644 Figure 10. Seasonal scatter plot of stability change (shade; $S_{p} \times 2500 \mathrm{~K} \mathrm{hPa}^{-1}$ ) at the top

645 of climatological boundary layer over land in SHF-BLH space for the second CSEOF

646 (regional warming) mode: (a) DJF, (b) MAM, (c) JJA, and (d) SON. The color dots 647 represent the occurrence frequency per day. 

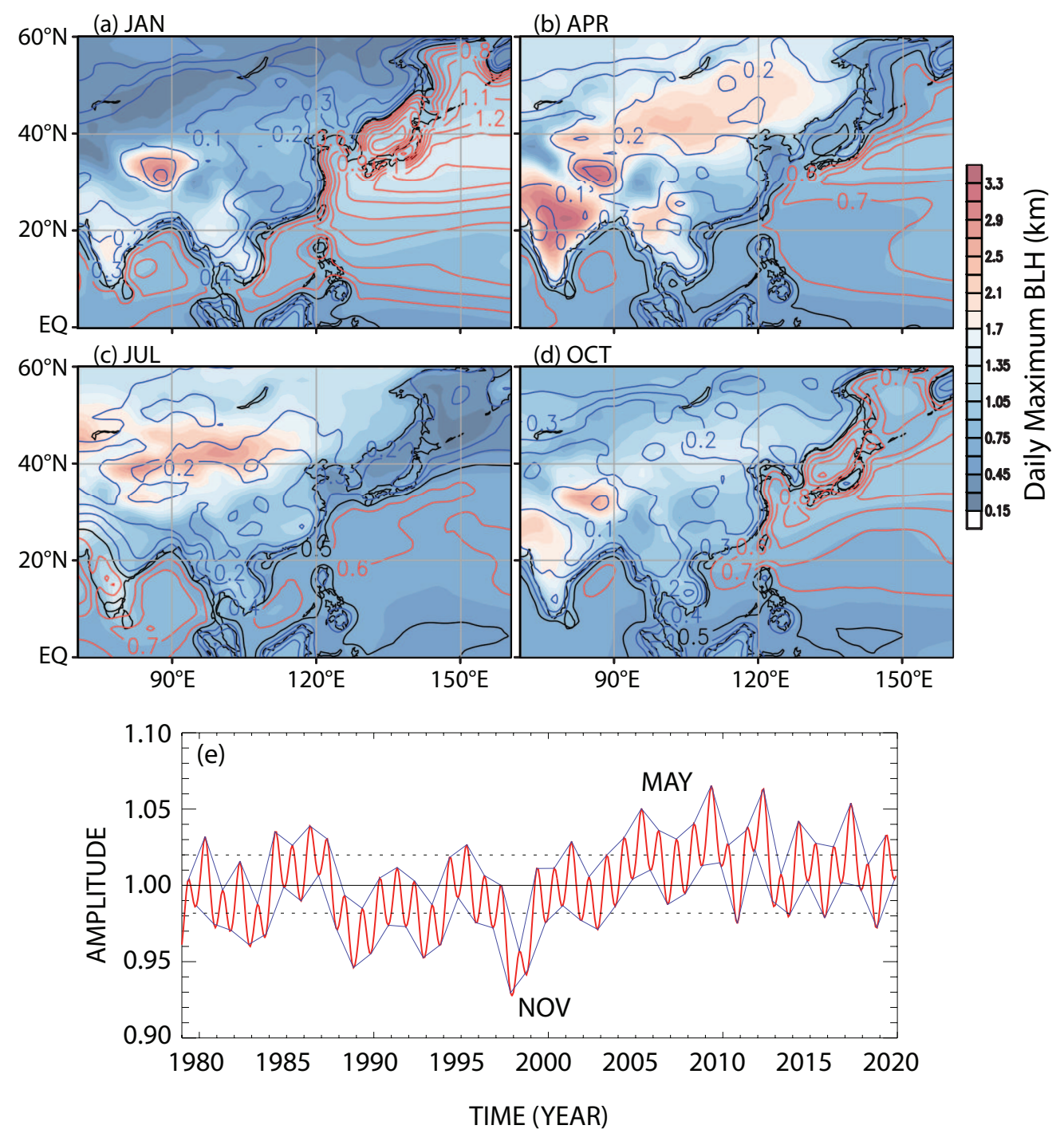

650 Figure 1. (a-d) The seasonal patterns of daily maximum (shade; $\mathrm{km}$ ) and daily 651 minimum (contour lines; $\mathrm{km}$ ) height of planetary boundary layer for the first CSEOF 652 mode (diurnal/seasonal cycle). (e) The normalized PC time series of the seasonal cycle. 653 Contour interval is $0.1 \mathrm{~km}$ with the black contour at $0.5 \mathrm{~km}$ (blue $<0.5 \mathrm{~km}<\mathrm{red}$ ). The 654 blue curves in (e) denote the PC time series in May and November, and the blue dotted 655 lines represent their mean values. 
(a) MON OF MAX BLH_MAX
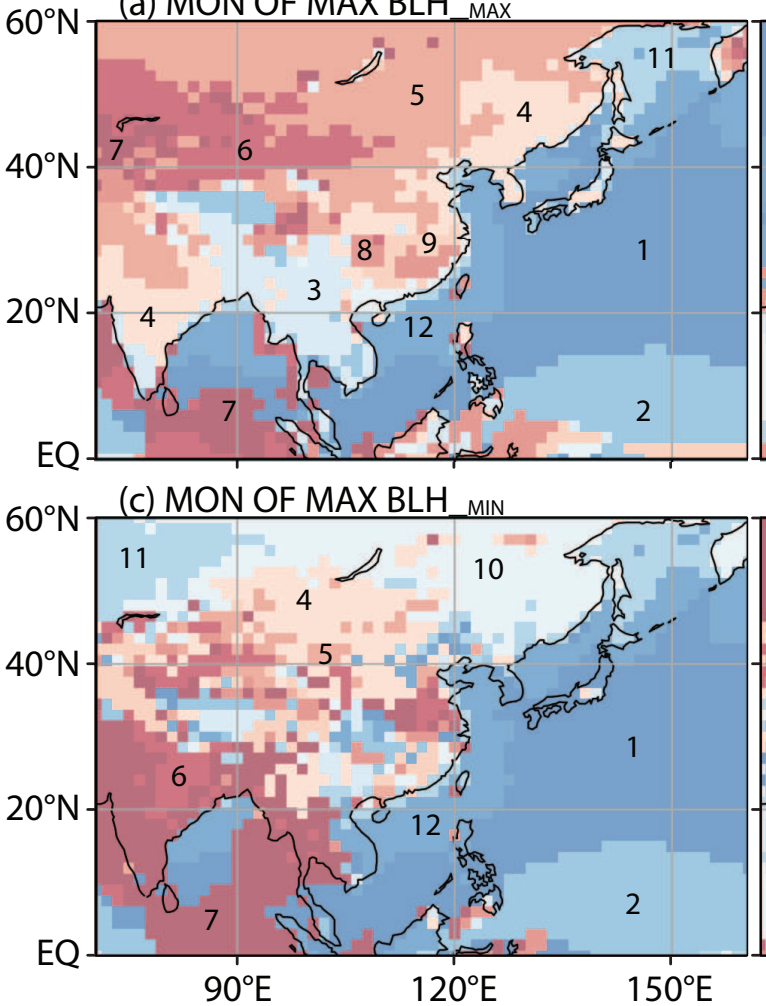

(d) MON OF MIN BLH_MIN

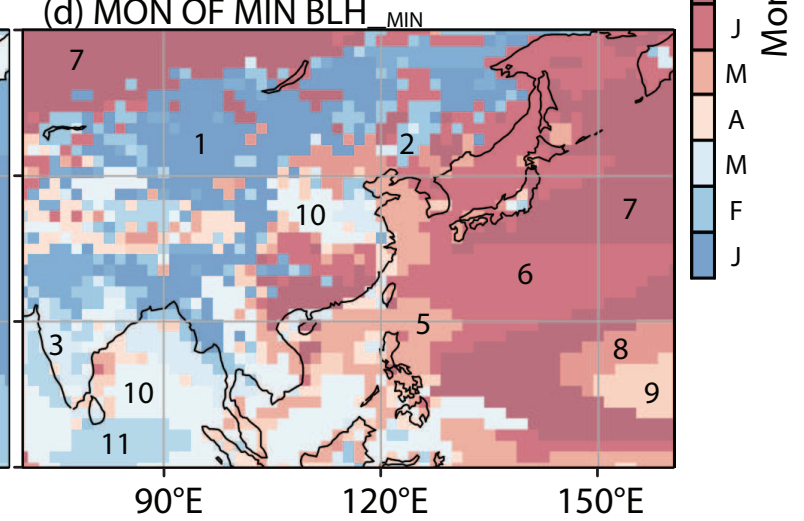

(b) MON OF MIN BLH_MAX

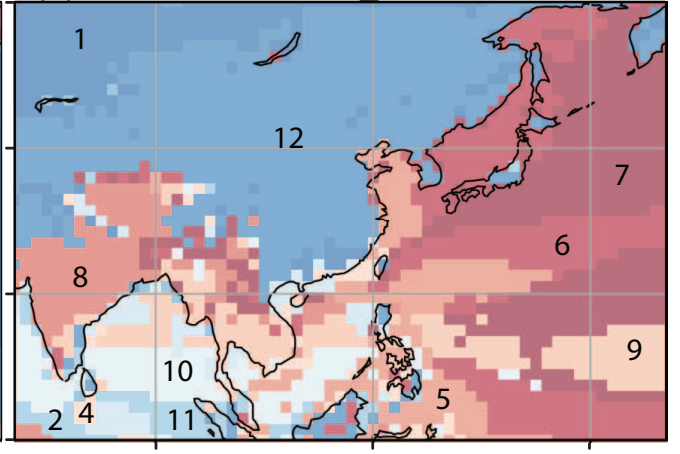

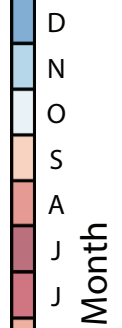

658 Figure 2. Month of (a) maximum BLH_max, (b) minimum BLH_max, (c) maximum BLH_min, and (d) minimum BLH_min. The red colors represent warm months and the blue colors 

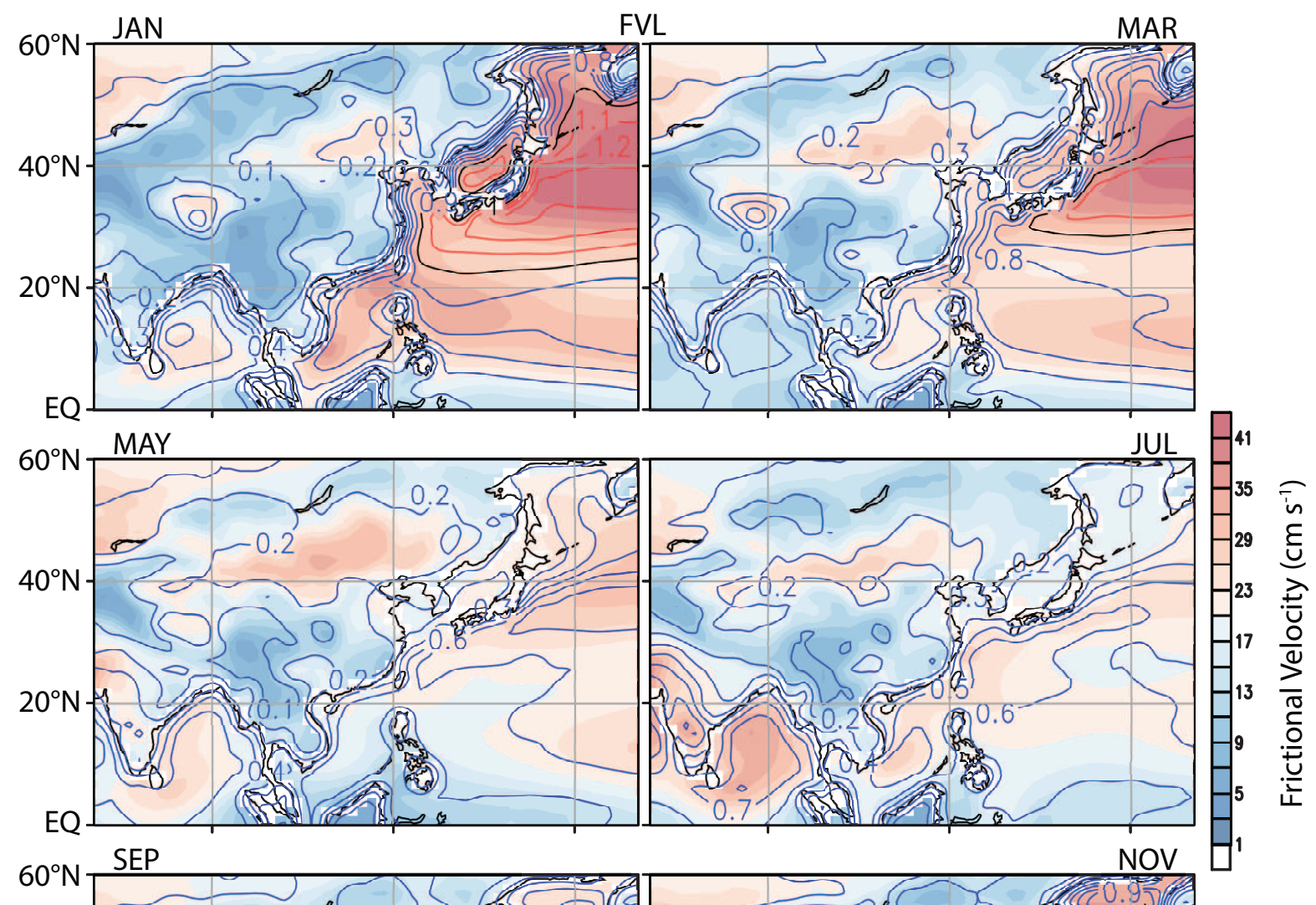

663 Figure 3. The patterns of frictional velocity (shade; $\mathrm{cm} \mathrm{s}^{-1}$ ) together with the minimum 664 boundary layer height (blue contours $<1.0$ (black) $<$ red contours at $0.1 \mathrm{~km}$ interval) for 665 the diurnal/seasonal cycle mode. 

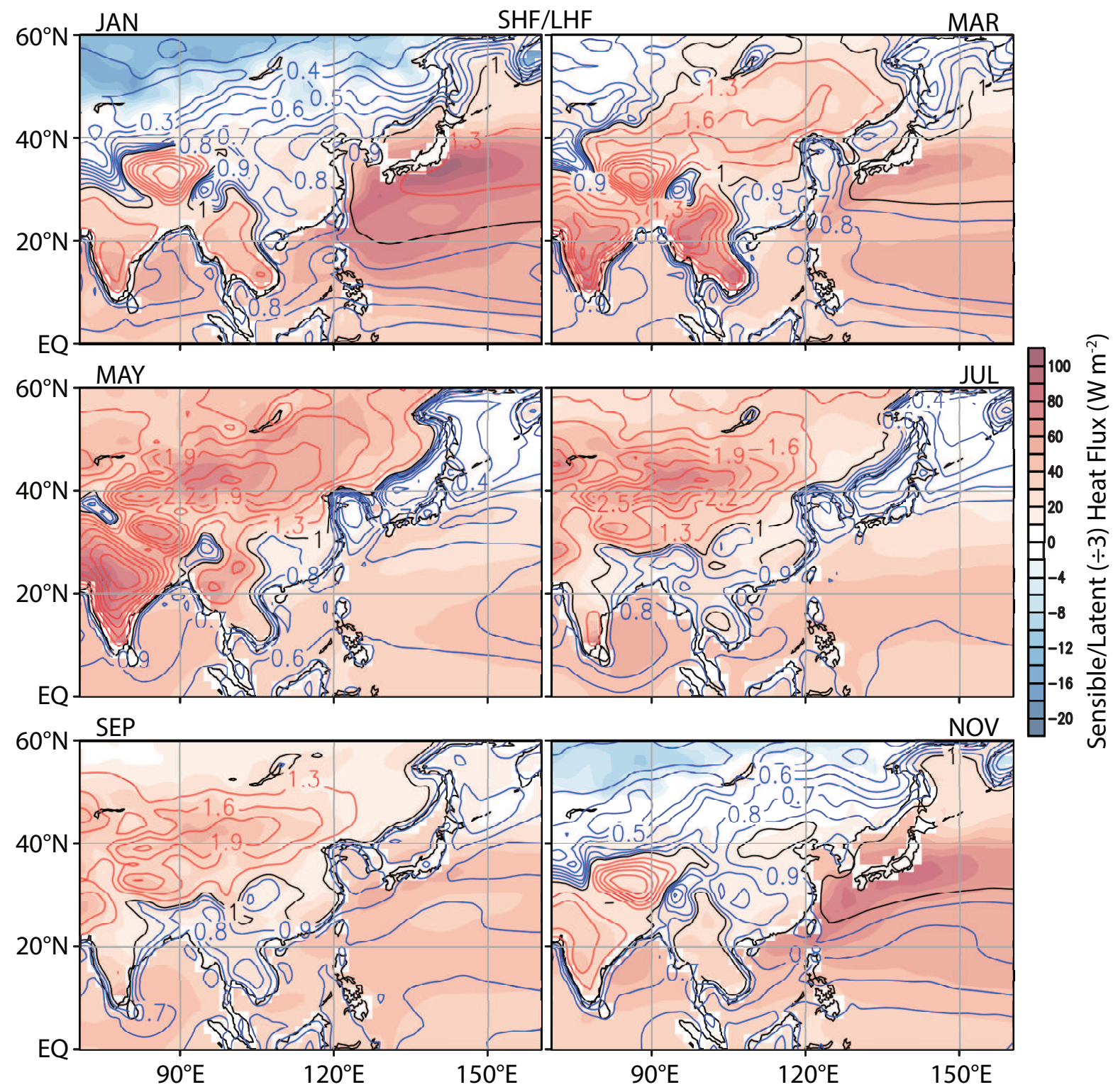

667

668 Figure 4. The patterns of sensible heat flux over the continent and latent heat flux $(\div 3)$ 669 over the ocean (shade; $\mathrm{W} \mathrm{m}^{-2}$ ) together with the maximum boundary layer height (blue 670 contour lines at $0.1 \mathrm{~km}$ interval $<1.0$ (black) < red contour lines at $0.3 \mathrm{~km}$ interval) for 671 the diurnal/seasonal cycle mode. 


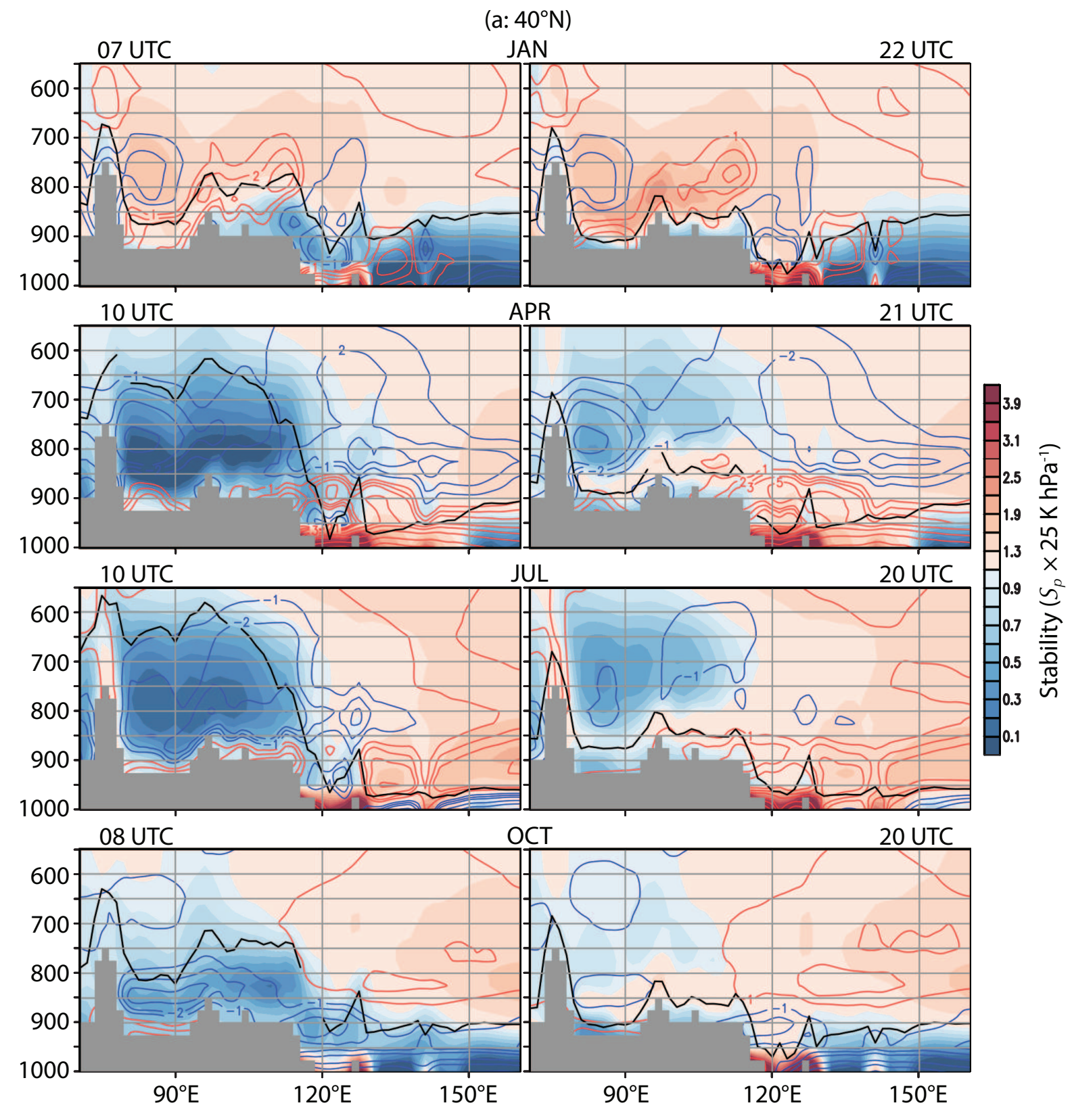

Figure 5. The vertical structure of stability (shade; $S_{p} \times 25 \mathrm{~K} \mathrm{hPa}^{-1}$ ) and its change due 675 to regional warming (blue $<0<$ red contours; $S_{p} \times 2500 \mathrm{~K} \mathrm{hPa}^{-1}$ ), and the boundary 676 layer height (thick black line) at the approximate time of the maximum height (left 677 column) and the minimum height (right column): (a) $40^{\circ} \mathrm{N}$, (b) $25^{\circ} \mathrm{N}$, and (c) $55^{\circ} \mathrm{N}$. 


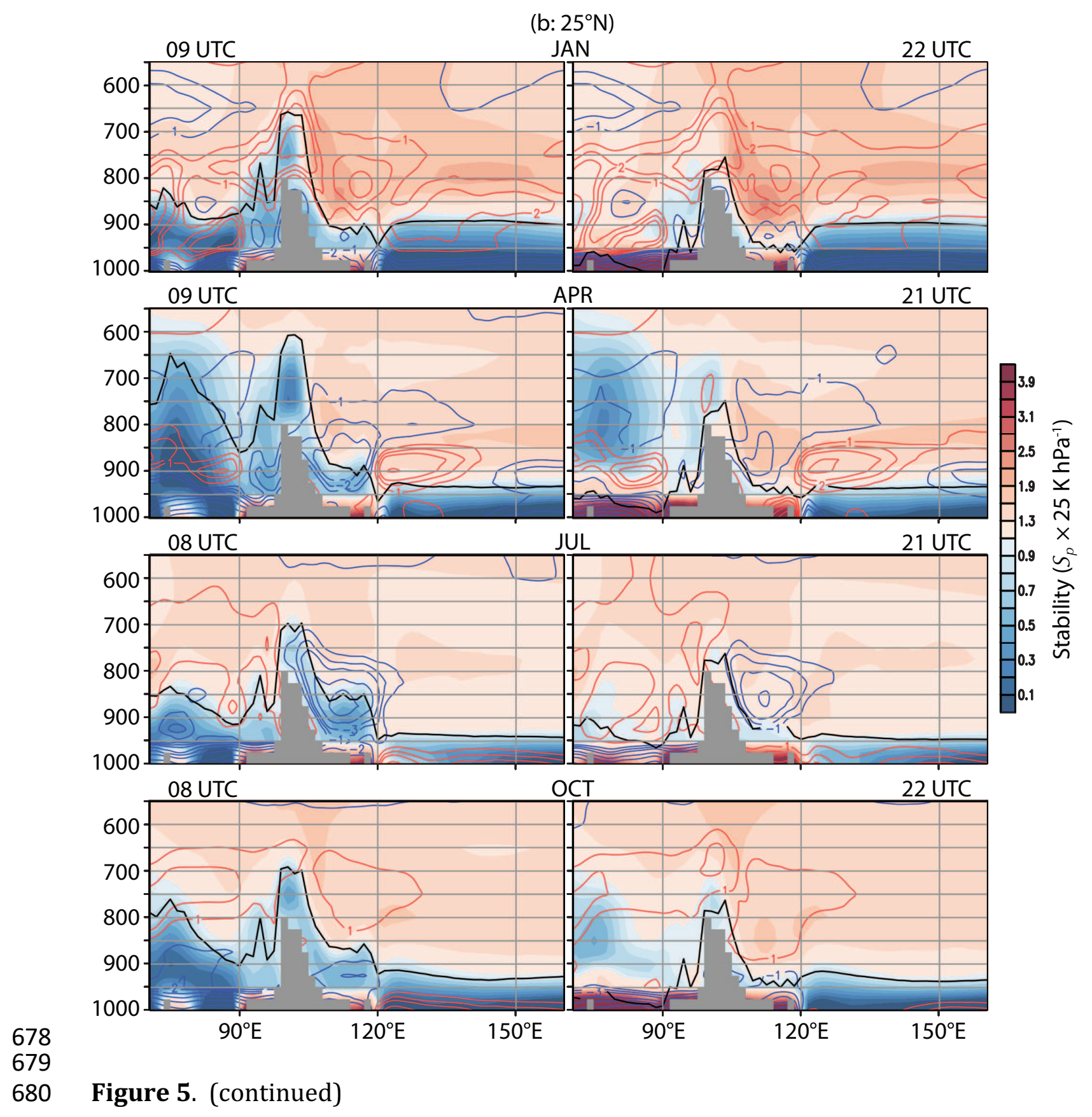




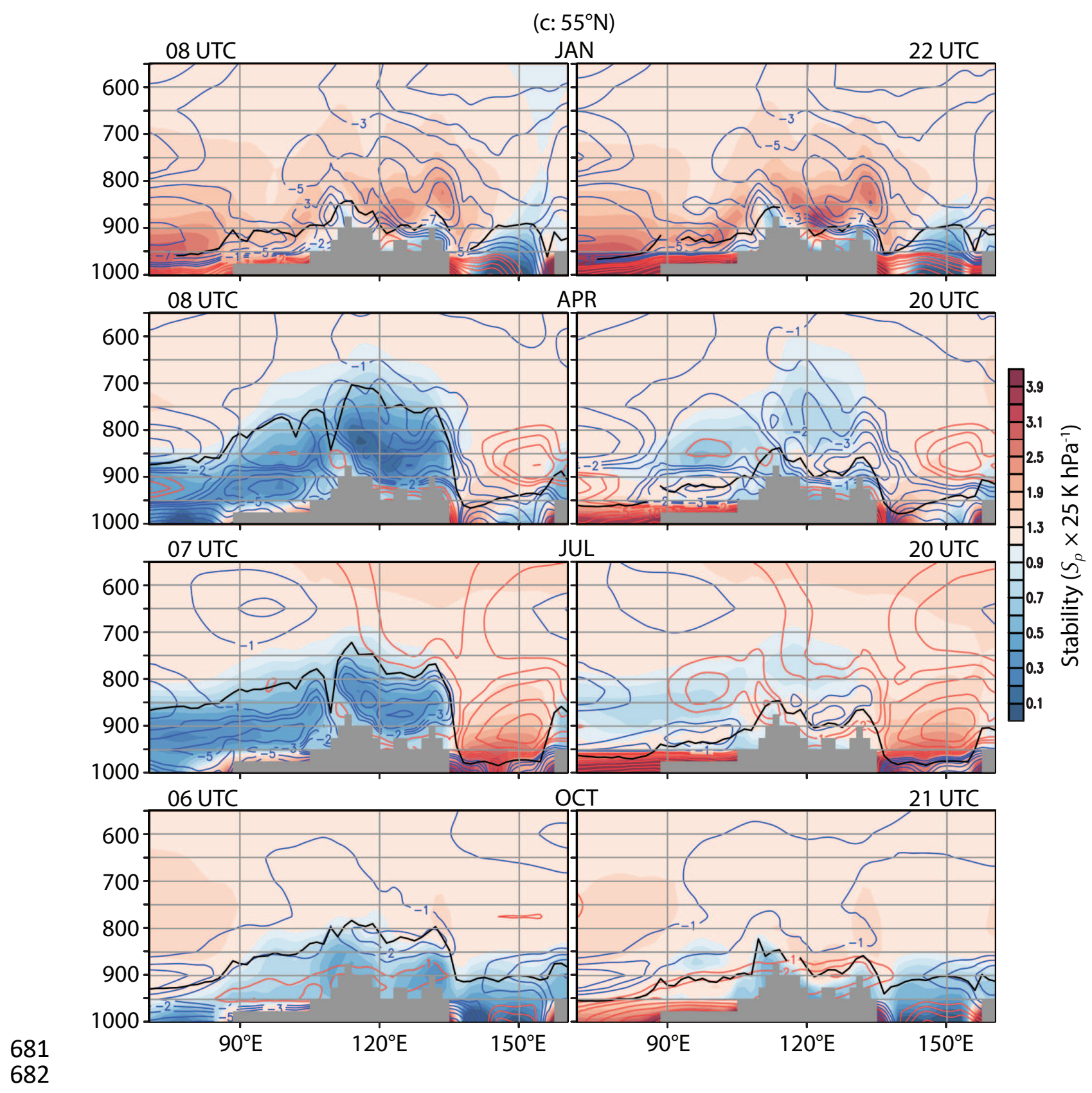

683 Figure 5. (continued) 


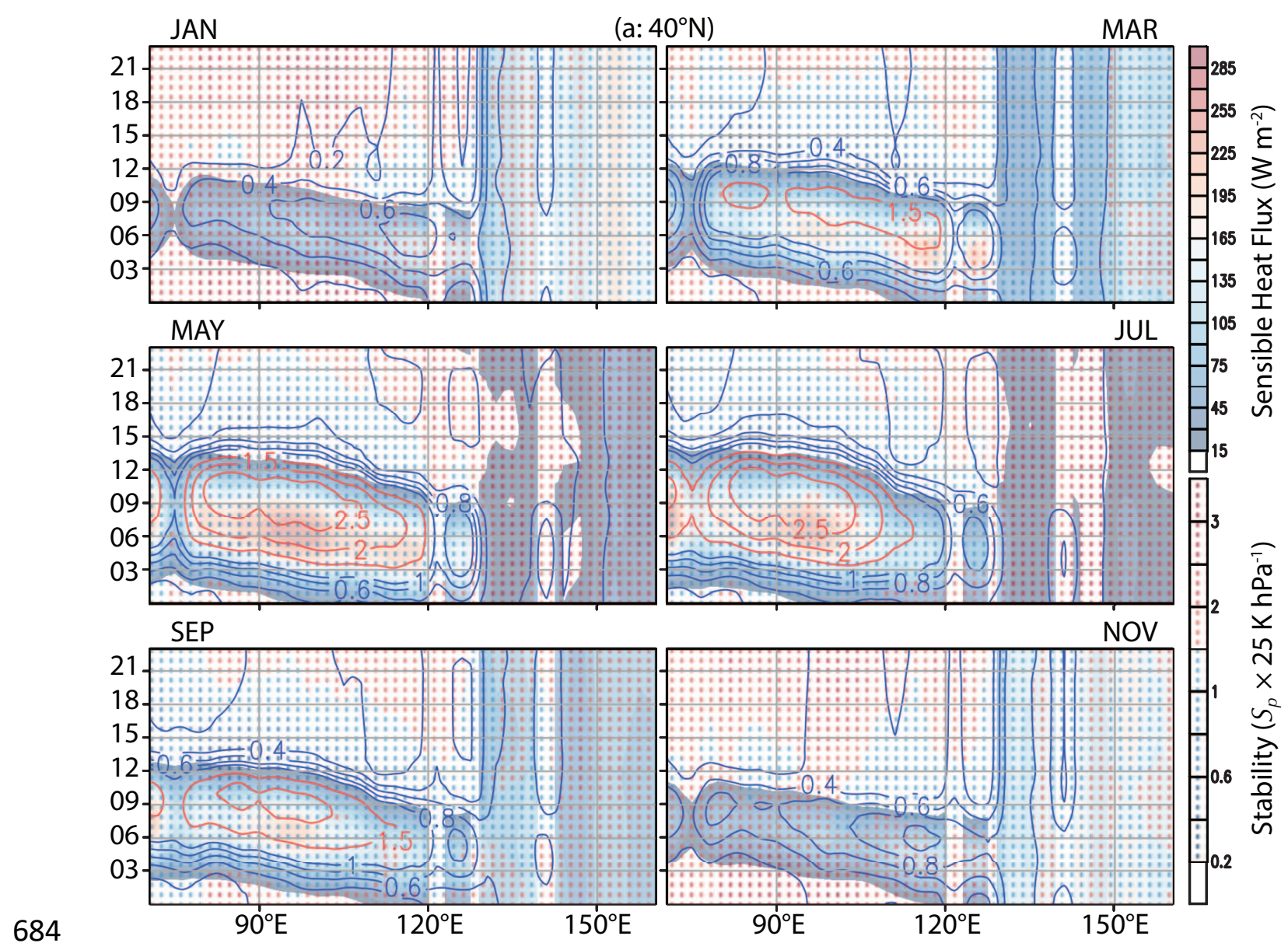

685

686 Figure 6. The diurnal structure of boundary layer height (contours; $0.2 \mathrm{~km}$ interval up 687 to $1.0 \mathrm{~km}$ and $0.5 \mathrm{~km}$ interval thereafter) together with sensible heat flux (shade; $\mathrm{W} \mathrm{m}^{-2}$ ) 688 over the continent, latent heat flux (shade; $\mathrm{W} \mathrm{m}^{-2}$ ) over the ocean, and stability at the 689 top of the boundary layer (color dots; $S_{p} \times 25 \mathrm{~K} \mathrm{hPa}^{-1}$ ) for the first CSEOF mode 690 (diurnal/seasonal cycle). The upper color bar represents the shading levels for heat flux, 691 and the lower color bar the dot color levels for stability: (a) $40^{\circ} \mathrm{N}$, (b) $25^{\circ} \mathrm{N}$, and (c) $55^{\circ} \mathrm{N}$. 


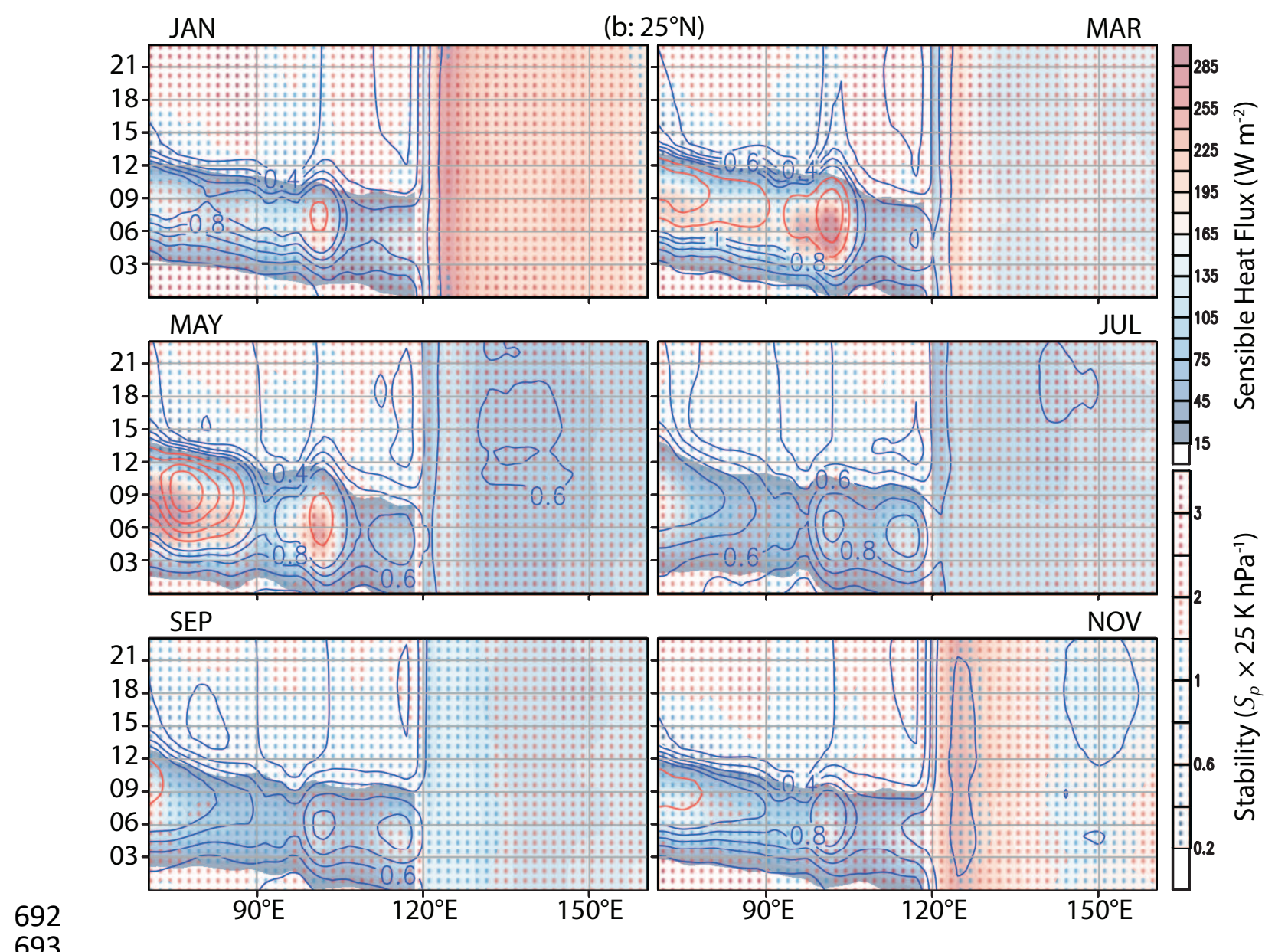

693

694 Figure 6. (continued) 


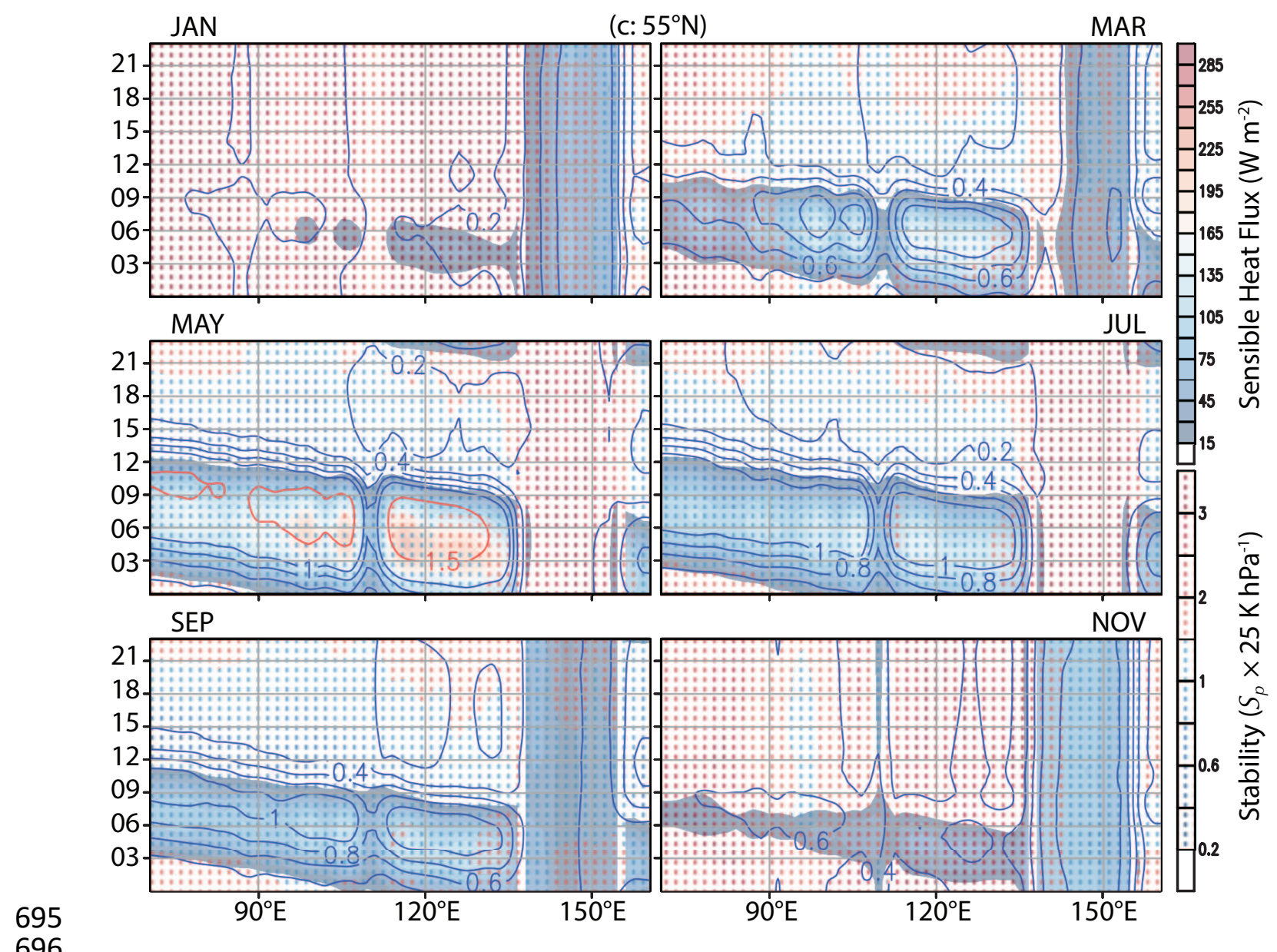

696

697 Figure 6. (continued) 

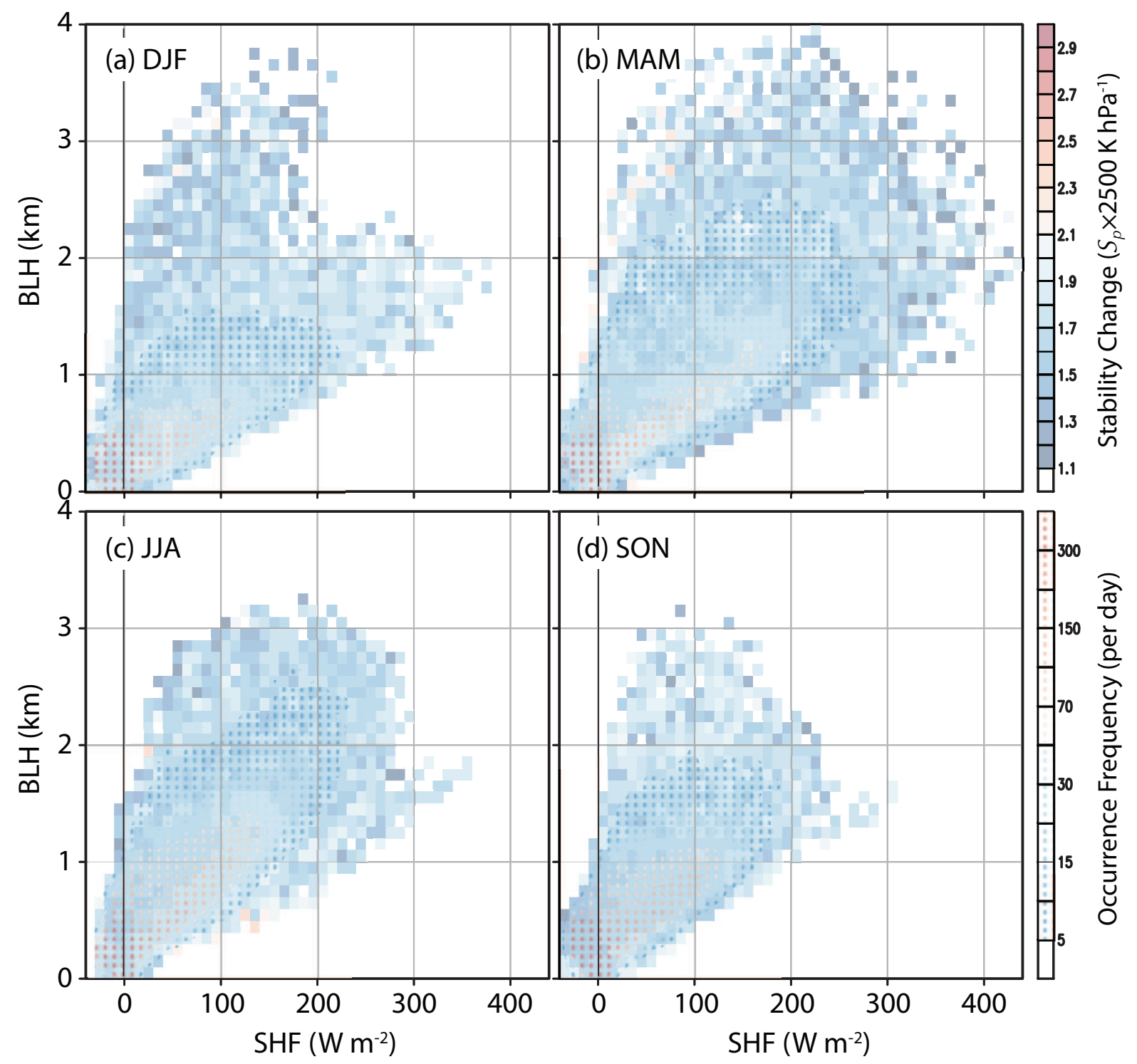

700 Figure 7. Seasonal scatter plot of stability (shade; $S_{p} \times 25 \mathrm{~K} \mathrm{hPa}^{-1}$ ) over land in SHF701 BLH space for the first CSEOF mode (diurnal/seasonal cycle): (a) DJF, (b) MAM, (c) JJA, 702 and (d) SON. The colored dots represent the occurrence frequency per day. 

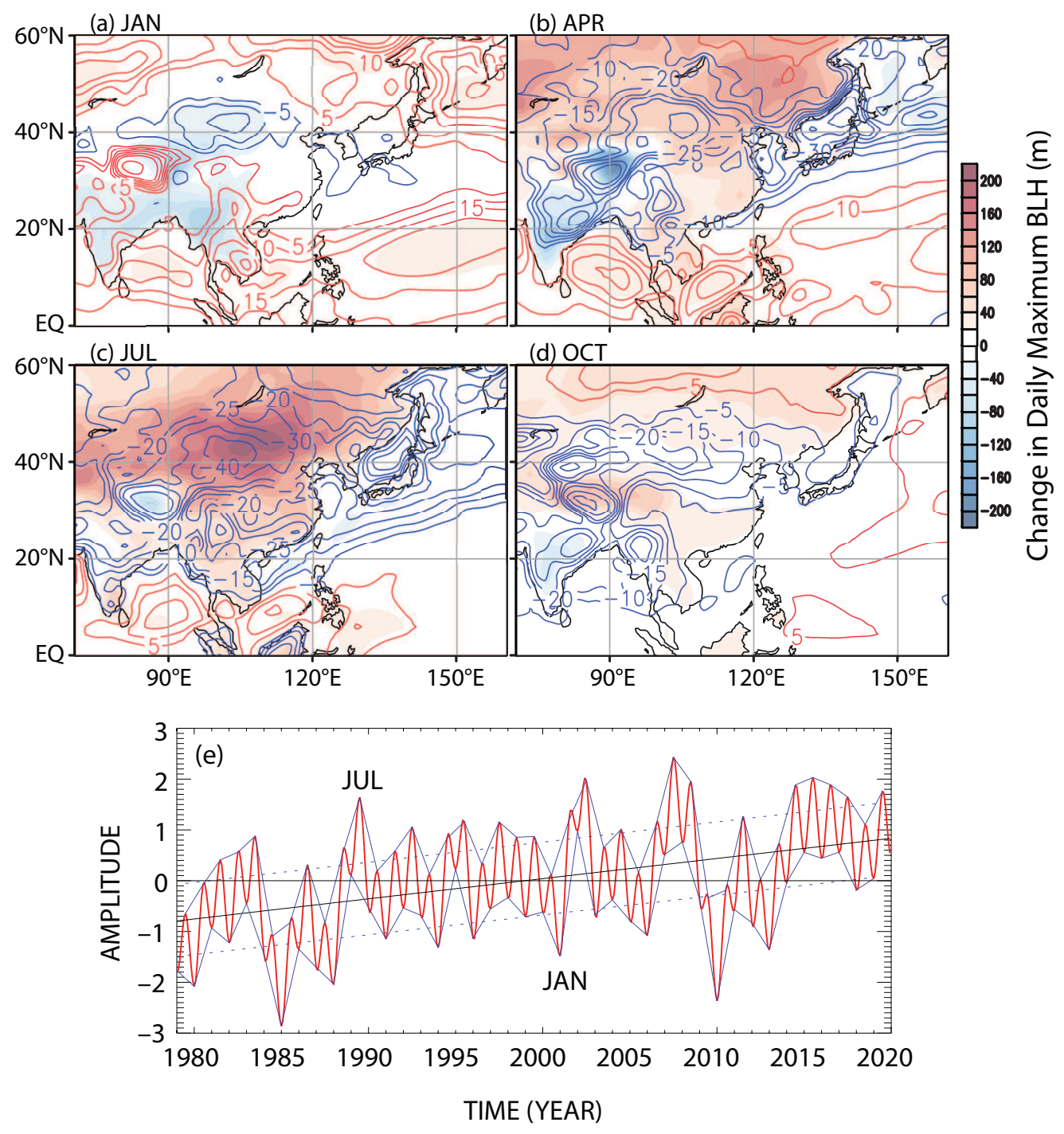

Figure 8. (a-d) The seasonal patterns of daily maximum (shade; $m$ ) and daily minimum (contour; $\mathrm{m}$ ) height of planetary boundary layer for the warming mode. (e) The PC time series of the warming mode (red curve) together with the linear trend (black line). Contour interval is $5 \mathrm{~m}$ (blue $<0<$ red). The blue curves represent the PC time series for January and July, and the blue dotted lines their respective trends. 

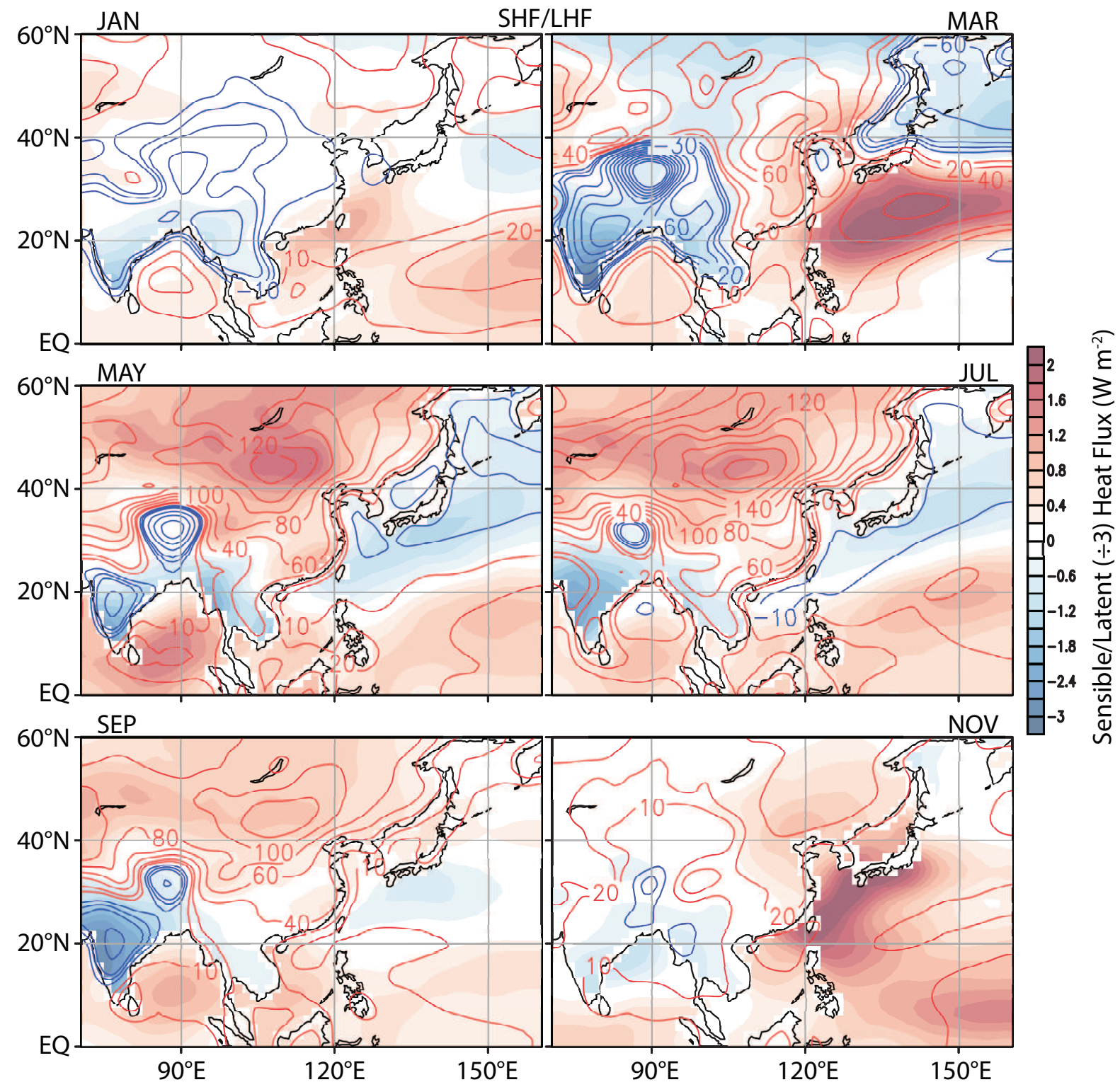

Figure 9. The patterns of anomalous sensible heat flux over the continent and 713 anomalous latent heat flux $(\div 3)$ over the ocean (shade; $\mathrm{W} \mathrm{m}^{-2}$ ) together with the change 714 in maximum boundary layer height (blue $<0<$ red contour lines at $\pm 10,20$, and at $20 \mathrm{~m}$ 715 interval thereafter) for the warming mode. 


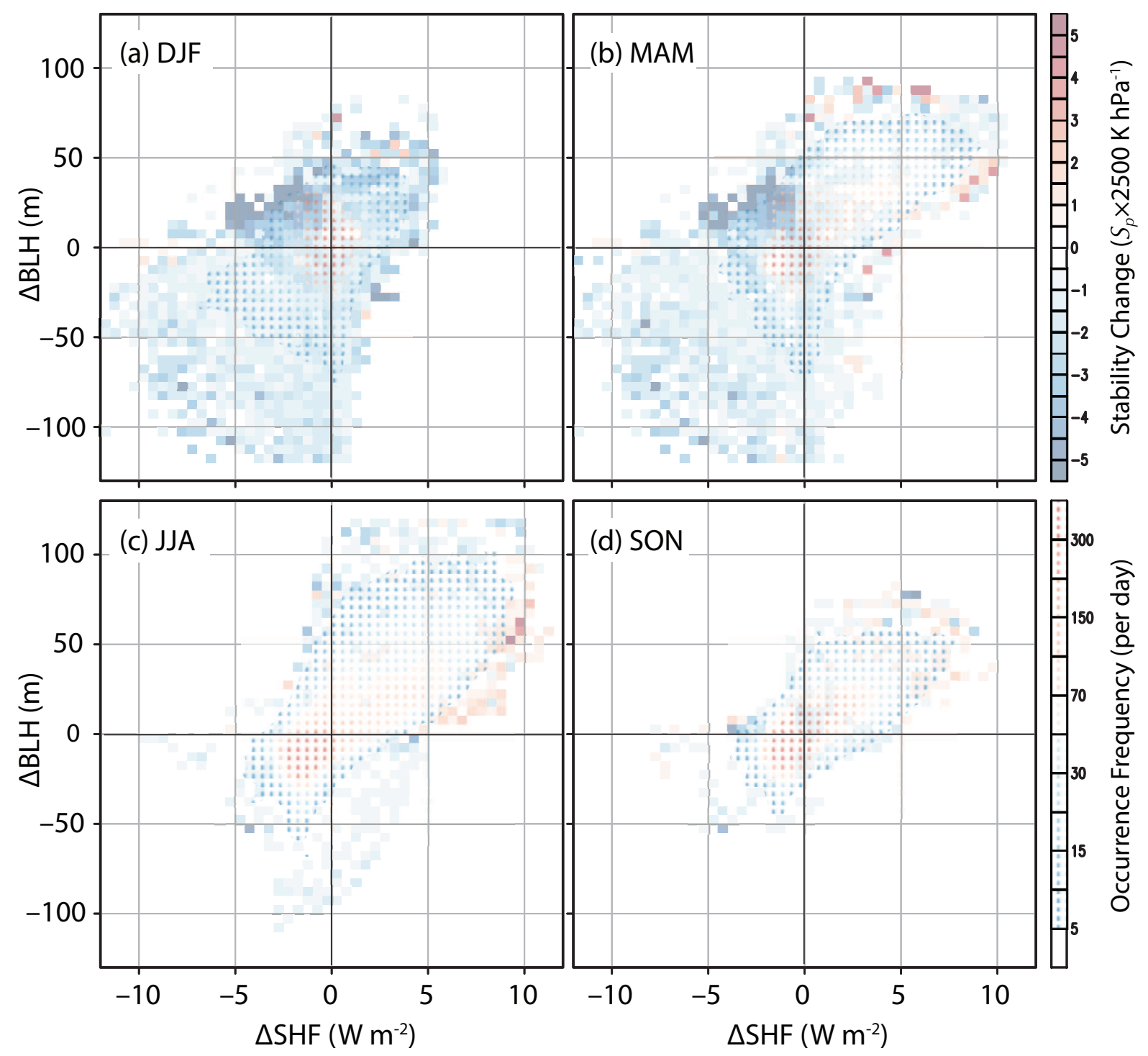

718 Figure 10. Seasonal scatter plot of stability change (shade; $S_{p} \times 2500 \mathrm{~K} \mathrm{hPa}^{-1}$ ) at the top 719 of climatological boundary layer over land in SHF-BLH space for the second CSEOF 720 (regional warming) mode: (a) DJF, (b) MAM, (c) JJA, and (d) SON. The color dots 721 represent the occurrence frequency per day. 


\section{Supplementary Files}

This is a list of supplementary files associated with this preprint. Click to download.

- MovieS1a.mov

- Movies1b.mov

- MovieS1c.mov

- Movies1d.mov

- pblsupp.pdf 